\title{
The Effect of Recast on Students' Speaking Skill Based on Their Learning Strategies
}

\author{
Adhi Nurhartanto \\ Lampung University \\ radhyo16@gmail.com
}

\begin{abstract}
Many studies have been conducted to find the effect of recast as a feedback on students. Some studies have also revealed that recast is found to be less effective. This study is aimed to find the effect of recast to students with different learning strategies in an EFL context in Indonesia. The study is conducted using quasiexperimental design. The research instruments include LLSQ questionnaire and speaking test. The results reveal that recast may be effective for students with certain dominance of learning strategies.
\end{abstract}

Keywords: recast, speaking skills, learning strategies

\section{A. INTRODUCTION}

Generally, it is agreed that one of the teacher's role is giving corrective feedback to the students' exercises. This area has been observed by Lyster and Ranta (1997), Ellis, Loewen, and Erlam (2006), Mackey (2006), and Goo and Mackey (2013). These researches have conducted researches which elaborate the use of corrective feedback and its effectiveness in laboratory and classroom studies. Studies on corrective feedback show that the results of corrective feedback are positive to students' language production. These studies have mentioned that corrective feedback is important and contributes to second language acquisition.

A study recommends that corrective feedback is useful is shown by Lyster and Ranta (1997). Their study examines six types of oral corrective feedback, namely: recasts, elicitation, clarification requests, metalinguistic feedback, explicit correction and elicitation. Lyster and Ranta's (1997) study mentions that even though recasts appeared to be the most common error correction used by teachers, it is found to be ineffective since only $30 \%$ of the recasts are followed by the uptake by the students while the other $70 \%$ goes unnoticed. Lyster and Ranta (1997) defines uptake as 'student's utterance that immediately follows the teacher's feedback and that constitutes a reaction in some way to the teacher's intention to draw attention to some aspect of the student's initial utterance. In most studies, the use and usability of corrective feedback is based on the uptake, in terms of the learners' immediate response to the feedback but the validity of immediate uptake as an indication of acquisition in a long term is questionable.

The finding mentions that recasts are mostly used by teachers to correct students' error but found to be less-effective. Since then more researchers make comparative study of recasts with other types of corrective feedback. The results are mostly similar to mention that recasts are less effective compared to other types of feedback but still more effective than those without any 
treatments (Ellis, et.al, 2006; Ellis, 2007). However, the studies have proven that the use of corrective feedback is important to accelerate students' language acquisition.

Corrective feedback is claimed by Schmidt (1994) as the importance of noticing and noticing the gap in L2 acquisition. Schmidt's definition of corrective feedback seems to give a direction of the claim of why error correction goes unnoticed. Krashen's (1983) Affective Filter Hypothesis which points out that error correction has the immediate effect of putting the students on the defensive and therefore, harmful for language acquisition. This theory has since made the use of direct correction is limited. Teachers hesitate to give direct correction and it is resulted in the fossilization of the errors made. Questions related to giving correction are still remained. Hendrickson (1978) formulate the questions on error correction as when should learner's error be corrected?, which errors should be corrected?, how should errors be corrected?, and who should do the correction?. Krashen's theory seems to put learners in unlimited time and let them speak when they feel ready, when the language is learned or acquired.

Since then, the studies which compare recasts with other types of corrective feedback have been done which mostly compare between recasts with other type of feedback. In their research in low-intermediate of second language class, Ellis, Loewen, and Erlam (2006) apply recasts as implicit feedback and metalinguistic explanation as explicit feedback in correcting students' errors in regular past tense. Their research concludes that explicit feedback in the form of metalinguistic information is more superior than the implicit feedback in the form of recasts in oral imitation test, grammaticality judgment test, and metalinguistic knowledge test in delayed posttest.

In other research, Mackey (2006) discusses feedback in the form of instructed second language learning which inserts feedback in a game-show quiz activity involving questions, plurals, and past tense forms. Mackey mentions that the purpose of the study is to determine whether the interactional feedback is associated with learners' reports about noticing. The study concludes that there may be association between noticing and learning.

Other study from Sheen (2008) investigates the level of language anxiety related to learners' ability in improving the accuracy when the learners are provided with corrective feedback in the form of recasts. The result shows that the low anxiety group which is treated by recasts as the corrective feedback scores significantly higher than high-anxietyrecast- group and the control group. The finding shows that language anxiety is a factor that influence not only whether recasts lead to modified output but also whether they promote learning.

In their library study, Goo and Mackey (2013) mentions that comparing recasts with other types of corrective feedback seems to be standing in shaky foundation for some reasons because recasts are operationalized as single type while the others often used in multiple types. Moreover, they argued that recasts and prompts-like clarification requests, metalingusitic feedback, and elicitations- are not to be compared and may work synergistically to effect positive changes in L2 development (Goo and Mackey, 2013). The type of recasts, such as

$\mathrm{S} \quad$ : To her is good thing

$\mathrm{T} \quad$ : Yeah, for her it's a good thing 
S : Because she got a lot of money there

(Loewen and Philp, 2006)

Seems to let the student under confusion because it seems like responding to the student's speech and does not give opportunity for the students to make an uptake and repair the error while the other types of feedback gives more information such as 'Pardon?' (clarification request), 'you need another preposition' (metalinguistic feedback), 'to her?' (repeat and change of tone in repetition). Based on this view, the research might be expanded, not only to compare the types of feedback, but also to explore on how corrective feedback is effective. Again, Goo and Mackey (2013) propose research on the interaction of the effectiveness of corrective feedback to individual differences in cognitive capacity.

Different view comes from Goo and Mackey (2013) which states that comparing recasts to other types of feedback is comparing one apple to oranges. Their view comes from the fact that other feedbacks are modified feedbacks which lead to modified output opportunity in the form of clarification requests, metalinguistic feedback, elicitations, and repetitions, while recasts are giving the complete correct form of the target language without waiting for the output.

Researchers have agreed that feedback is contributive to second language learning. The factors of affective filter, students' response to feedback, types of feedback, and its effect on students' acquisition of the language seems to be teachers' consideration in conducting the classroom activity.

Ellis and Schmidt (1997) mention that Second Language Acquisition's important foci is the examination of cognitive processes in second language learning. Moreover, Mackey et al. (2000) mentions that two cognitive processes which plays important role in SLA is attention and awareness. From the point of view of learning strategies, cognitive processes are useful to explain two basic issues, namely: mental representation and mental processing (Setiyadi, 2012). Moreover, Setiyadi (2012) adds mental representation may refer to how students memorized what they have learned, or experienced in their life by remembering things in their native languages, while mental processing, on the other hand deals with cognitive processing. From the definitions above, it is clear that cognitive processes include all activities related to mental processing.

Therefore, this study is aimed to investigate the effectiveness of recasts on students, based on their dominance in using language learning strategy categories, namely; cognitive category, metacognitive category, and social category. Research question is as follows. Is student's dominance on certain learning strategies influence their acceptance on recasts?

\section{B. METHOD}

This research is a crosssectional design where the data were collected from a relatively large sample at one point in their language development (Dulay, Burt, Krashen, 1982). It was done with deductive approach where researcher had preconceived notion or expectation about L2 phenomena to be investigated (Suparman, 2009). This research involved students who are taking basic classes of listening, reading, structure, speaking, and writing. In the end, researcher picked ten students to apply the recasts treatment. The subjects of this research came from university 
majoring non English Department and did not use English frequently.

Before the test was done, the students were asked to take a questionnaire based on the Language Learning Strategies Questionnaires (LLSQ) which were taken form Setiyadi (2012). The questionnaires were given at the beginning of the class to categorize the students in certain dominant learning strategies category. It is hoped that in each class all categories of language learning strategy users, namely; cognitive category, metacognitive category, and social category are represented in the class.

The data was collected from telling the family member's daily activities. The study noted students' speech production of someone's daily activities. So, the data taken were in the Simple present form for the third person which focuses in verb+s. In this technique, students were asked to tell one of the family member's daily activities. In the first chance, the students told the story focusing on the use of verb+s with the teacher gave recasts when the students did not make the right sentences. In the second chance, after a few minutes, students were asked to tell again about the daily activities of the other family member (different from the first), based on their own understanding and diction without any interference from the teacher. The uptake and modified output was noted.

\section{DISCUSSION}

Uptake is defined as the output produced by learners as a result of feedback that they receive after they make utterance which may consist of modified output or not (Ellis, 2005). From these definitions, uptake can be seen as a product after feedback is given. However, the result of uptake cannot be guarantee as correct outputs. Uptake can be seen as the direct response of the feedback.

Meanwhile, repair is referred by Lyster and Ranta (1997) as the correct reformulation of an error as uttered in a single student turn and not to the sequence of turns, resulting in the correct reformulation.

To answer the research question, the following data was gained from the questionnaires.

Table 1. Number of Recasts, Uptakes, and Repairs

\begin{tabular}{|c|l|c|c|c|c|c|}
\hline No. & Name & $\begin{array}{c}\text { Sentence } \\
\text { Made }\end{array}$ & $\begin{array}{c}\text { Recasts } \\
\text { Made }\end{array}$ & Uptakes & $\begin{array}{c}\text { Uptakes } \\
\text { Percentage }\end{array}$ & Repairs \\
\hline 1 & MAr & 14 & 2 & 2 & $100 \%$ & 2 \\
\hline 2 & IY & 10 & 10 & 1 & $10 \%$ & 1 \\
\hline 3 & Ar & 10 & 4 & 3 & $75 \%$ & 3 \\
\hline 4 & RAM & 7 & 7 & 4 & $57 \%$ & 4 \\
\hline 5 & INV & 10 & 7 & 2 & $29 \%$ & 2 \\
\hline 6 & DTA & 8 & 8 & 1 & $13 \%$ & 1 \\
\hline 7 & SMN & 11 & 9 & 0 & $0 \%$ & 0 \\
\hline 8 & FA & 10 & 8 & 4 & $50 \%$ & 3 \\
\hline 9 & LS & 7 & 5 & 4 & $80 \%$ & 3 \\
\hline 10 & MAf & 12 & 10 & 1 & $10 \%$ & 1 \\
\hline \multicolumn{2}{|l}{ Total } & $\mathbf{9 9}$ & $\mathbf{7 0}$ & $\mathbf{2 2}$ & $\mathbf{3 1 \%}$ & \\
\hline
\end{tabular}


The data had described about how students of Indonesian EFL learners responded to the corrective feedback used by their teacher, in this case recasts as the corrective feedback. This finding is in line with Lyster and Ranta (1997) which shows that $69 \%$ of the recasts go without any uptake from the students. This finding contributes to their finding that recasts can be seen as ineffective. Even from student No.7, the percentage of uptake was $0 \%$. Student No.7 only replied by "yes" without doing any uptakes. This data indicates that students' acceptance on corrective feedback was different from each other.

From what had been found, it may be necessary to look back to
Schmidt's (1994) statement that teachers need to show the importance of noticing and noticing the gap in L2 acquisition. Mackey et al. (2000) mentions that two cognitive processes which plays important role in SLA are attention and awareness. These two theories have probably shown the cause. The student's lacking of awareness and attentions have failed him to notice what went wrong from the sentence he produced. From the simple present tense sentences (verb $1+\mathrm{s}$ ), that were produced by the students, most of the students were not able to give additional $+\mathrm{s}$, even though the verbs used had been taught in the classroom.

Table 2. Errors Percentation Without Recasts

\begin{tabular}{|c|l|c|c|c|}
\hline No. & Name & $\begin{array}{c}\text { Sentence } \\
\text { Made }\end{array}$ & Errors & $\begin{array}{c}\text { Errors } \\
\text { Percentage }\end{array}$ \\
\hline 1 & MAr & 7 & 3 & $43 \%$ \\
\hline 2 & IY & 7 & 4 & $57 \%$ \\
\hline 3 & Ar & 11 & 8 & $73 \%$ \\
\hline 4 & RAM & 7 & 7 & $100 \%$ \\
\hline 5 & INV & 7 & 7 & $100 \%$ \\
\hline 6 & DTA & 7 & 5 & $71 \%$ \\
\hline 7 & SMN & 8 & 8 & $100 \%$ \\
\hline 8 & FA & 12 & 0 & $0 \%$ \\
\hline 9 & LS & 8 & 5 & $63 \%$ \\
\hline 10 & MAf & 5 & 5 & $100 \%$ \\
\hline & & $\mathbf{7 9}$ & $\mathbf{5 2}$ & $\mathbf{6 6} \%$ \\
\hline
\end{tabular}

In the more natural speech, without any intervention from the teacher, which were taken only 30 minutes after the first interview, 66\% of the sentences produced by the students were inaccurate. There were errors contained in the sentences. From 79 sentences produced, 52 sentences had errors. These also showed that the recasts given by the teacher were not memorable and had failed to give notification of what went wrong.

The result also showed that one student, No.8, made no errors from his twelve sentences to describe about his sister's daily activities. It showed that individual differences 
may cause in how a language is acquired. From the first interview, student No. 8 showed that he made errors in $50 \%$ of his sentences (Table
1), but the next result (Table 2) he showed good accuracy. Therefore, there may be some ways to see the individual differences in each student.

Table 3. Score of Learning Strategies

\begin{tabular}{|l|l|c|c|c|}
\hline No. & Name & Cognitive & Meta & Social \\
\hline 1 & MAr & 3.8 & 4.0 & 3.4 \\
\hline 2 & IY & 2.5 & 3.6 & 3.6 \\
\hline 3 & Ar & 3.3 & 4.2 & 3.0 \\
\hline 4 & RAM & 3.5 & 4.2 & 3.6 \\
\hline 5 & INV & 3.4 & 3.6 & 3.8 \\
\hline 6 & DTA & 3.6 & 3.6 & 2.6 \\
\hline 7 & SMN & 2.9 & 3.0 & 3.4 \\
\hline 8 & FA & 3.3 & 3.8 & 3.2 \\
\hline 9 & LS & 2.7 & 3.8 & 3.4 \\
\hline 10 & MAf & 2.9 & 4.0 & 2.8 \\
\hline
\end{tabular}

Based on the research question, this research tries to find which learning strategy is probably effective to make recasts is noticeable. From the errors made, only student No. 1 and No. 8 with each made $57 \%$ of correctness and $100 \%$ of correctness. Both of the students also had highest score in metacognitive strategy. Setiyadi (2012) mentions that metacognition involves processes related to monitoring and evaluating what has been done and planning what to do in acquiring another language. Moreover, he added that metacognitive strategies include self-direction, self-monitoring, selfevaluating and self-correcting.

From the strategy employed by the two students, altogether, both of them put 'I try to speak with myself to improve my speaking' and 'I notice my English mistakes, and use that information to help me do better' as as always true of me, which means these strategies were employed by them. Therefore, it is probably necessary to teach this strategy to the students to improve their speaking accuracy.

\section{CONCLUSIONS}

Based on the findings, it can be concluded that the skill to notify what went wrong in their speech, is different from one another. These individual differences should be considered before giving the corrective feedback. Corrective feedback, represented by recasts can take role to wrap up what have been learned by the students, but the effectiveness is still arguable. This study has showed that it can be effective to certain type of student. From the point of view of learning strategy, it can also be taught to students to reflect how the successful students use the learning strategy to increase their speaking ability, specifically speaking accuracy. 


\section{REFERENCES}

Dulay, H., Burt, M., and Krashen, S. (1982). Language Two. New York: Oxford University Press.

Ellis, Rod. (2005). Instructed Second Language Acquisition A Literature Review. Ministry of Education: New Zealand

Ellis, Rod., Loewen, Shawn., \& Erlam, Rosemary. (2006). Implicit and Explicit Corrective Feedback and The Acquisition of L2 Grammar. Studies of Second Language Acquisition 28 339-368. Cambridge University Press: USA.

Goo and Mackey (2013). The case against the case against recasts.

Studies in Second Language Acquisition , 2013, 35, 127- 165.

Krashen, Stephen D. (1982). Principles and Practice in Second Language Acquisition. Phoenix ELT: Great Britain.

Mackey, Alison. (2006). Feedback, noticing and instructed second language learning. Applied Linguistics 27/3: 405-430. Oxford University Press: Oxford
Mackey, A., S. Gass,. And K. McDonough. (2000). How do learners perceive implicit negative feedback? Studies in Second Language Acquisition 22.

Lyster, Roy. and Ranta, Leila. (1997). Corrective feedback and learner uptake: Negotiation of form in communicative classrooms. Studies in Second Language Acquisition, 20, 37 - 66. Cambridge University Press: USA.

Setiyadi, Ag. Bambang. (2012). English Learning Strategies in An EFL Setting in Indonesia. Halaman Moeka: Jakarta.

Sheen, Younghee. (2008). Recasts, Language anxiety, modified output, and L2 learning. Language Learning 58:4, December 2008.

Suparman, Ujang. 2009. Qualitative Research for Language Teaching and Learning. Bandung: Arfino Raya 